Check for updates

London, UK

Cite this as: BMJ 2020;371:m4257 http://dx.doi.org/10.1136/bmj.m4257 Published: 2 November 2020

\section{Covid-19: T cell response lasts for at least six months after infection, study shows}

\author{
Jacqui Wise
}

Robust cellular immunity persists for at least for six months after even mild or asymptomatic SARS-CoV-2 infection, research has shown. ${ }^{1}$

The study of 100 people showed that all had a cellular immune response against SARS-CoV-2 six months after infection although the size of response was 50\% higher in those who had experienced symptomatic disease.

There has been concern that the cellular immune response following covid-19 infection may not be sustained. "This data is reassuring," lead study author Paul Moss, from the University of Birmingham, told a Science Media Centre briefing on 2 November. "However, it does not mean that people cannot be re-infected. We need to have much larger population studies to show that." Moss also added that the findings "can't be taken as confirmation that an 'immunity passport' would be feasible."

The study from the UK Coronavirus Immunology Consortium and Public Health England, which is published as a preprint and has not yet been peer reviewed, is believed to be the first in the world to show that a robust cellular memory against the virus persists for at least for six months.

The researchers collected serum and blood samples from a cohort of more than 2000 clinical and non-clinical healthcare workers, including 100 who tested seropositive for SARS-CoV-2 in March and April 2020. The average age of the donors was 41 (range 22 to 65 years old); 23 were men and 77 were women. None of them were hospitalised with covid-19-56 people had mild or moderate symptoms and 44 were asymptomatic.

Serum samples were collected monthly to measure antibody levels and blood samples were taken after six months to measure the $\mathrm{T}$ cell response using an ELISPOT and ICS analysis. The study found that virus specific $\mathrm{T}$ cells were detectable in all donors at six months.

Antibody levels fell by around 50\% during the first two months after infection but then plateaued. The magnitude of the $\mathrm{T}$ cell response at six months was strongly correlated with the magnitude of the peak antibody response, the study found.

Moss said the finding that the $\mathrm{T}$ cell response was $50 \%$ higher in those who had experienced symptoms did not necessarily mean that asymptomatic people may be more susceptible to reinfection as they may just be better at fighting off the virus without the need to generate a large immune response.

The findings have implications for vaccine development. The cellular response was directed against a range of proteins from the virus, including the spike protein that is being used as a target in most vaccine studies. The study authors suggested that as $\mathrm{T}$ cell responses were also directed against additional nucleoprotein and membrane proteins these could also be valuable targets for future vaccines strategies.

"This is promising news-if natural infection with the virus can elicit a robust $\mathrm{T}$ cell response then this may mean that a vaccine could do the same," said Fiona Watt, executive chair of the Medical Research Council.

Charles Bangham, chair of immunology at Imperial College London, said, "This excellent study provides strong evidence that T cell immunity to SARS-CoV-2 may last longer than antibody immunity."

He added, "These results provide reassurance that, although the titre of antibody to SARS-CoV-2 can fall below detectable levels within a few months of infection, a degree of immunity to the virus may be maintained. However, the critical question remains: do these persistent $\mathrm{T}$ cells provide efficient protection against re-infection?”

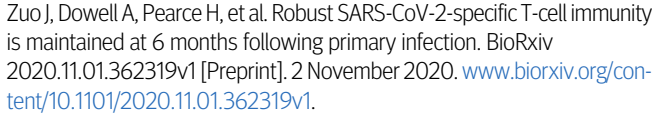

Zuo J, Dowell A, Pearce H, et al. Robust SARS-CoV-2-specific T-cell immunity is maintained at 6 months following primary infection. BioRxiv 2020.11.01.362319v1 [Preprint]. 2 November 2020. www.biorxiv.org/content/10.1101/2020.11.01.362319v1. 